\title{
Characterization of Disease Resistance Loci in the USDA Soybean Germplasm Collection Using Genome-Wide Association Studies
}

\author{
Hao-Xun Chang, Alexander E. Lipka, Leslie L. Domier, and Glen L. Hartman
}

All authors: Department of Crop Sciences, University of Illinois, Urbana, IL 61801; and third and fourth authors: USDA-Agricultural Research Services, Urbana.

Accepted for publication 20 April 2016.

\begin{abstract}
Chang, H.-X., Lipka, A. E., Domier, L. L., and Hartman, G. L. 2016. Characterization of disease resistance loci in the USDA soybean germplasm collection using genome-wide associations. Phytopathology 106:1139-1151.

Genetic resistance is a key strategy for disease management in soybean. Over the last 50 years, soybean germplasm has been phenotyped for resistance to many pathogens, resulting in the development of diseaseresistant elite breeding lines and commercial cultivars. While biparental linkage mapping has been used to identify disease resistance loci, genome-wide association studies (GWAS) using high-density and highquality markers such as single nucleotide polymorphisms (SNPs) has become a powerful tool to associate molecular markers and phenotypes.

The objective of our study was to provide a comprehensive understanding of disease resistance in the United States Department of Agriculture Agricultural Research Service Soybean Germplasm Collection by using phenotypic data in the public Germplasm Resources Information Network and public SNP data (SoySNP50K). We identified SNPs significantly associated with disease ratings from one bacterial disease, five fungal diseases, two diseases caused by nematodes, and three viral diseases. We show that leucine-rich repeat (LRR) receptor-like kinases and nucleotidebinding site-LRR candidate resistance genes were enriched within the linkage disequilibrium regions of the significant SNPs. We review and present a global view of soybean resistance loci against multiple diseases and discuss the power and the challenges of using GWAS to discover disease resistance in soybean.
\end{abstract}

Development of plant breeding strategies has been facilitated by advancements in biotechnology. Before the use of biotechnology, plant breeders relied on phenotypic selection to move desired traits into elite lines. With the advent of restriction enzymes and polymerase chain reaction, DNA markers were used to assist in trait selection. However, marker assisted selection using the early generation of DNA markers, such as restriction fragment-length polymorphism, amplified fragment length polymorphism, and simple sequence repeat (SSR) markers, had limited success because of low coverage, low throughput, and high cost (Yang et al. 2015). The capabilities of array-based technologies (e.g., Illumina BeadArray and Affymetrix GeneChip) and next generation sequencing (e.g., genotypingby-sequencing) to acquire high-quality and high-density single nucleotide polymorphism (SNP) markers in a high-throughput and low-cost manner provoked a second revolution in plant breeding (Barabaschi et al. 2016).

In contrast to linkage mapping conducted in experimental populations arising from biparental crosses, a genome-wide association study (GWAS) is typically conducted in a diversity panel, which captures historical recombination events that have occurred during the evolution of the sampled individuals. Consequently, false positive marker-trait associations arising from population structure and relatedness are likely to be present in a typical GWAS if unaccounted for in the statistical model (Lipka et al. 2015). As such, the unified mixed linear model (MLM) (Yu et al. 2006), which includes both fixed and random effect covariates accounting for population

Corresponding author: G. L. Hartman; E-mail address: glen.hartman@ars.usda.gov

*The $\boldsymbol{e}$-Xtra logo stands for "electronic extra" and indicates that 20 supplementary figures and two supplementary tables are published online.

http://dx.doi.org/10.1094/PHYTO-01-16-0042-FI

This article is in the public domain and not copyrightable. It may be freely reprinted with customary crediting of the source. The American Phytopathological Society, 2016. structure and relatedness, is widely used in a typical plant GWAS. Although quantitative phenotypes (e.g., height, weight, and yield) are commonly assessed in a GWAS, ordinal phenotypes (e.g., severity level from 1 to 5) or binary case-control phenotypes (e.g., susceptible or resistant) have also been assessed in GWAS (Rincker et al. 2016b). While ordinal phenotypes may be treated as quantitative phenotype in the unified MLM, binary phenotypes may require different approaches, such as the Pearson's $\chi^{2}$ test or logistic regressions (Anderson et al. 2010; Clarke et al. 2011; Zondervan and Cardon 2007). To reflect the fact that a typical phenotype is controlled by more than one gene, modifications to the unified MLM that allow multiple associated markers to be in one statistical model, such as the multilocus mixed model (Segura et al. 2012), the multivariate linear mixed model (Zhou and Stephens 2014), and models that consider epistasis (Wang et al. 2015), are beginning to be used in the plant GWAS community.

Soybean (Glycine max (L.) Merr.) is one of the most important crops worldwide and is second to maize in production in the United States (Hartman et al. 2015). Soybean production has increased steadily from 20 million metric tons produced in 1963 to over 90 million metric tons produced in 2013, with an estimated $11 \%$ annual loss caused by diseases (Hartman et al. 2015). Many management strategies are used to reduce the impact of soybean diseases, including rotation, pesticide application, and planting of resistant cultivars. One of the earliest reports of disease resistance in soybean dates back to the 1920s, when resistance to bacterial blight and pustule were described (Lehman and Woodside 1929; Woodworth and Brown 1920). However, as more pathogens became constraints to production and others evolved to overcome deployed resistance loci, there arose a need to discover novel sources of resistance. The United States Department of Agriculture Agricultural Research Service (USDA-ARS) maintains the Soybean Germplasm Collection, which contains over 20,000 plant introductions (PIs) from 87 countries, making it the second largest soybean genetic pool after a collection in China (Smýkal et al. 2015). The USDA collection has been used to identify resistance to many diseases, and the resulting 
phenotypic information is available from the Germplasm Resources Information Network (GRIN) (www.ars-grin.gov). There are now over 13 soybean diseases with available data in GRIN, and a brief literature review for resistance mapping to these diseases is provided below.

Bacterial pustule (BP) is caused by Xanthomonas axonopodis pv. glycines. The first resistant locus, named $\operatorname{rxp}$ (resistance to $X$. phaseoli), was reported as a single recessive allele from PI 548445 (Hartwig and Lehman 1951) and was mapped to chromosome 17 between two SSR markers (Satt486 and Satt372) (Narvel et al. 2001). Fine-mapping further narrowed the rxp locus to a 33-kb region between two SNP markers, SNUSSR17_9 and SNUSNP17_2\&_12, where two candidate genes were found (Kim et al. 2010). Additional minor quantitative trait loci (QTL) on chromosomes 4, 5, 10, 13, 17, and 19 were reported to be associated with BP resistance (Kim et al. 2011; Van et al. 2004).

The soilborne fungus Cadophora gregata causes brown stem rot (BSR). The major soybean resistance loci against $C$. gregata was reported on chromosome16; this includes Rbsl from L78-4094, $R b s 2$ from PI 437833 (Hanson et al. 1988), and $R b s 3$ from PI 437970 and 'BSR101', which was the first mapped $R b s$ locus (Webb 1997; Willmont and Nickell 1989). Rbsl and Rbs2 were later mapped between SSR markers Satt215 to Satt431 and Satt244 to Satt431, respectively (Bachman et al. 2001). Recent linkage mapping and GWAS have shown that the three putative Rbs loci may be allelic and located in a $0.34 \mathrm{Mb}$ region on chromosome 16 harboring three nucleotide-binding site leucine-rich repeat (NBSLRR) resistance genes (Glyma.16g169600, Glyma.16g169700, and Glyma.16g169900) (Rincker et al. 2016a and b).

Diaporthe stem canker (DSC) is caused by Diaporthe phaseolorum var. caulivora and $D$. phaseolorum var. meridionalis. Four dominant nonallelic loci conditioning resistance to D. phaseolorum var. caulivora were identified: $R d c 1$ and $R d c 2$ in 'Tracy M', $R d c 3$ in 'Crockett', and Rdc4 in 'Dowling' and 'Hutcheson' (Bowers et al. 1993; Kilen and Hartwig 1987; Tyler 1996). A later study screened these cultivars to different isolates of $D$. phaseolorum var. caulivora and D. phaseolorum var. meridionalis, and the four loci $R d c l$ to $R d c 4$ were renamed to $R d m l$ to $R d m 4$, because these cultivars displayed resistance to $D$. phaseolorum var. meridionalis but not to D. phaseolorum var. caulivora (Pioli et al. 2003). In addition, 'Dowling' and 'Hutcheson' displayed different sensitivities to two D. phaseolorum var. meridionalis isolates, CE109 and CE112, which led to the identification of Rdm5 in 'Hutcheson' (Chiesa et al. 2009; Pioli et al. 2003). To our knowledge, none of the $R d m$ resistance genes have been mapped. None of the soybean lines harboring $R d m 1$ to $R d m 5$ displayed full resistance to isolates of D. phaseolorum var. caulivora. Nevertheless, 'Hutcheson' and an Argentine edamame germplasm line, G47, have been reported to be moderately resistant to D. phaseolorum var. caulivora (Benavidez et al. 2010).

Since an early report of Phytophthora root and stem rot (PRR) resistance (Bernard et al. 1957), 14 loci associated with resistance to Phytophthora sojae have been identified, including Rps 1 (six allelic types), Rps7, Rps 9, RpsYu25, and RpsYD29 on chromosome 3, Rps 2 and RpsUN2 on chromosome 16; Rps3 (three alleles) and Rps 8 on chromosome 13; Rps4, Rps5, Rps6, and RpsJS on chromosome 18 (Lee et al. 2013; Lin et al. 2013; Nguyen et al. 2012; Sugimoto et al. 2012; Sun et al. 2011, 2014; Zhang et al. 2013). Most commercial soybean cultivars have resistance to this pathogen. Although the most commonly used allele is Rps $1 k$, other alleles including Rpsla and Rpslc are also deployed (Chawla et al. 2013).

Fusarium virguliforme is a soilborne fungus that causes sudden death syndrome (SDS) in the United States (Hartman et al. 2015). Soybean resistance to $F$. virguliforme is quantitative (Lightfoot 2015). Genetics of SDS resistance are complicated, not only because resistance to SDS is sensitive to environmental factors and other organisms (e.g., soybean cyst nematode [SCN] Heterodera glycines [HG]) but, also, because of the complexity of the hostpathogen interaction. The fungus infects only below-ground parts of soybean plants early in the season and produces phytotoxins that are translocated to leaves, in which they induce foliar symptoms later in the growing season (Chang et al. 2016b). Accordingly, soybean resistance to $F$. virguliforme can be divided into two parts, i.e., foliar resistance to phytotoxins and resistance to root rot (Lightfoot 2015). Altogether, more than 50 QTL have been reported for SDS resistance (Anderson et al. 2015; Luckew et al. 2013). Association studies also have been conducted for SDS resistance, some of which identified associated markers in the vicinity of previously reported QTL (Bao et al. 2015; Chang et al. 2016b; Swaminathan et al. 2016; Wen et al. 2014; Zhang et al. 2015).

Soybean rust (SBR) is caused by Phakopsora pachyrhizi. Typical susceptible foliar symptoms are tan lesions, often with more than two uredinia per lesion with abundant sporulation. Resistance has been defined as foliar symptoms displaying reddish brown lesions with less than two uredinia per lesion or no visible lesions (Hartman et al. 2011; Kelly et al. 2015). Resistance locus Rppl in PI 200492 (McLean and Byth 1980) and a distinct allele, Rppl-b, identified $1 \mathrm{cM}$ from Rppl in PI 594538A, were both mapped to chromosome 18 (Chakraborty et al. 2009; Hyten et al. 2007). Rpp2 in PI 230970 and rpp2 in PI224270 were mapped to chromosome 16 (Garcia et al. 2008; Silva et al. 2008). Rpp3 in PI 462312 and PI 416764 as well as Rpp?(Hyuuga) in 'Hyuuga' were mapped to chromosome 6 (Hossain et al. 2014; Hyten et al. 2009; Monteros et al. 2007). Rpp4 in PI 459025 was mapped to chromosome 18 (Silva et al. 2008) and Rpp5 in three PIs as well as rpp5 in PI 200456 were mapped to chromosome 3 (Garcia et al. 2008). Rpp6 in PI 567102B, a novel or Rpp6-allelic locus Rpp[PI 567068A], and Rpp6907 in Chinese line SX6907 were mapped to chromosome 18 (Chen et al. 2015; Harris et al. 2015; King et al. 2016).

Resistant loci in soybean to reniform nematode ( $\mathrm{RN})$, Rotylenchulus reniformis, have been reported on chromosomes 11, 18, and 19 from PI 437564 (Ha et al. 2007). A recent study reported and confirmed resistance in PI 567516C on chromosome 11 and 18 (Jiao et al. 2015a). These two loci overlap with loci for resistance to SCN, indicating the possibility of a shared resistance mechanism against $R$. reniformis and $H$. glycines (Jiao et al. 2015b; Wu et al. 2009).

Several dominant and recessive genes have been reported to provide resistance to $H$. glycines, including $R h g 1-3, R h g 4$, and Rhg5 (Concibido et al. 2004; Jiao et al. 2015b). More than 62 QTL associated with SCN resistance have been mapped (Gou et al. 2006). Association studies conducted on different HG types identified significant SNPs on chromosomes 2, 4, 5, 7 to 9, 11, 14, 16, 18, and 20 (Han et al. 2015) and on chromosomes 1, 2, 7, 8, 10 to 15 , and 18 to 20 (Vuong et al. 2015), and both studies confirmed loci Rhgl on chromosome 18 (Cook et al. 2012) and Rhg4 on chromosome 8 (Liu et al. 2012).

There has been no mapping study for Bean pod mottle virus (BPMV) tolerance or resistance, but there were many reports of resistance to Peanut mottle virus (PMV) and to Soybean mosaic virus (SMV). Three PMV resistance loci in soybean include two dominant loci, Rpvl in PI 96983 and Rpv3 in 'CNS', and one recessive locus, rpv2, in 'Peking' (Hill and Whitham 2014). The $R p v 1$ gene was mapped to chromosome 13 within $1.1 \mathrm{cM}$ of $R s v 1$, a resistant locus to SMV (Gore et al. 2002).

Soybean responses to SMV infection have been classified into three types: susceptible, necrotic, and resistance, depending on the soybean genotypes and the strains of SMV (Hill and Whitman 2014). In the United States, at least seven strains (G1 to G7) have been reported that induce different responses on differential soybean PIs (Cho and Goodman 1979; Zhou et al. 2015). While susceptible soybeans displayed typical viral symptoms such as mosaic and curling leaves in different severity levels, resistant soybeans generally have no symptoms and have no detectable or recoverable virus. Necrosis could be local necrotic spots, systemic necrosis, or bud blight that eventually limits plant growth. Although necrotic responses have been considered as hypersensitive interaction against SMV, SMV may still be capable of replication and 
movement (Cervantes-Martinez et al. 2015). Three loci control soybean resistance against SMV. Rsvl was first found (Kiihl and Hartwig 1979) and mapped on chromosome 13, which appears to be a dominant source with at least 10 allelic types. On the other hand, $R s v 3$ on chromosome 14 contains five allelic types, in 'Harsoy', 'L29', 'OX686', PI 61947, and PI 399091, while Rsv4 on chromosome 2 has three allelic types, from 'Beeson', V94-5152, and PI 88788 (CervantesMartinez et al. 2015; Ilut et al. 2016). In addition to dozens of allelic types of Rsv1, Rsv3, and Rsv4 reported in the United States, several resistant alleles were reported in China, including $R s c 7$ and $R s c 8$ on chromosome 2 in 'Kefeng No.1', Rsc15 on chromosome 6 in 'RN-9', $R s c 3 Q$ and $R s c 14 Q$ on chromosome 13 in 'Qihuang No.1', and Rsc4 on chromosome 14 in 'Dabaima' (Li et al. 2015).

The objective of our study was to associate the phenotypic data for diseases reported in the USDA-ARS GRIN Soybean Germplasm Collection with SNP markers derived from SoySNP50K (Song et al. 2013), using GWAS, and present a global view of soybean resistance loci available in public databases that could be used in the era of "next generation breeding" (Barabaschi et al. 2016).

\section{MATERIALS AND METHODS}

Phenotypic and genotypic data. Phenotypic data for 13 soybean diseases were obtained from the USDA-ARS GRIN database (www.ars-grin.gov). Disease severity rating and population size with available SNPs from SoySNP50K differed by each disease (Supplementary Table S1). SNP marker data were obtained from the SoySNP50K (www.soybase.org). Missing SNPs on each chromosome were imputed separately, using BEAGLE version 3.3.2 (Browning and Browning 2009), which resulted in a total of 42,449 SNP markers. When phenotype data were available for more than 2,000 soybean PIs, a minor allele frequency (MAF) of 0.01 was used as a cutoff. When phenotype data were available for less than 2,000 PIs, a MAF of 0.05 was used.

Association analyses. For each evaluated trait, a GWAS was conducted using the unified MLM (Yu et al. 2006) with population parameters previously determined (Zhang et al. 2010) in the GAPIT $\mathrm{R}$ package (Lipka et al. 2012). The initial MLM included principal components (PCs) (Price et al. 2006) and a kinship matrix (VanRaden 2008) that were used to account for population structure and familial relatedness. The Bayesian information criterion (BIC) was used to determine the optimal number of PCs needed to include as covariates in the MLM. For most of the evaluated traits, the BICbased model selection procedure selected the model with zero PCs as optimal, suggesting that either most of the traits were not strongly correlated with population structure or that the kinship matrix is accounting for population structure as well as familial relatedness. The Benjamini and Hochberg (1995) procedure was used to adjust for multiple testing at a false-discovery rate (FDR) of 5\%. When the initial GWAS identified at least one significant SNP at a 5\% FDR, the GWAS scan was rerun with most significant SNP as a covariate in the model. This procedure (i.e., conducting GWAS scans using the peak SNP from a previous GWAS as a covariate) was continued until no significant SNPs were found at 5\% FDR. For binary phenotypes (i.e., BPMV and PMV), signals detected by MLM were further confirmed by regional association tests (i.e., within \pm 10 Mbp of each signal), using Firth's logistic regression (Firth 1993). The R package ggbio was used to plot ideograms for significant SNPs (Yin et al. 2012).

Linkage disequilibrium (LD) decay and candidate gene enrichment analyses. Flanking SNPs located within $\pm 3 \mathrm{Mbp}$ of each significant SNP were used for assessing LD decay in TASSEL5 (Bradbury et al. 2007). A sliding window size of $50 \mathrm{bp}$ was used and heterozygous alleles were treated as missing data (Supplementary Table S2). A cutoff of squared allele-frequency correlation $\left(r^{2}\right)$ between pairs of SNPs equal to 0.2 was determined, using loess regression in $\mathrm{R}$ (Cleveland 1981). The genes within the LD decay region of peak SNPs were noted. In particular, the observed numbers of LRR-receptor-like kinase (RLK) and NBS-LRR genes, which have been shown previously to play a role in disease resistance (Afzal et al. 2008; Kang et al. 2012; Liu et al. 2015), in the LD decay region were compared with the number of LRR-RLK and NBS-LRR in the soybean genome (Schmutz et al. 2010), using a $\chi^{2}$ test for verifying enrichment significance.

\section{RESULTS}

Our GWAS identified novel SNPs associated with BP, BPMV, DSC, PMV, RN, SBR, SCN, and SDS resistance (Fig. 1). Among these diseases, resistance mapping for DSC and to BPMV was completed for the first time. To provide a view of the genetic composition around these SNPs and loci, genes located within the LD region of each significant SNP were summarized, and the top two observed annotations were LRR-RLK and NBS-LRR genes, which accounted for 3.38 and $3.45 \%$ of the total genes summarized from the LD decay regions (Supplementary Fig. S1). In the soybean genome, LRR-RLK and NBS-LRR genes are estimated at 1.03 and $0.69 \%$ of the total coding sequences, respectively (Afzal et al. 2008; Kang et al. 2012; Liu et al. 2015; Schmutz et al. 2010). The $\chi^{2}$ tests supported significant enrichment $(P<0.01)$ for both LRR-RLK and NBS-LRR genes in the LD decay region at $\alpha=0.05$.

BP resistance. Our GWAS identified three significant SNPs on chromosomes 1, 11, and 17. Two LRR-RLK resistance gene candidates (Glyma01g40560 and Glyma01g40590) were found

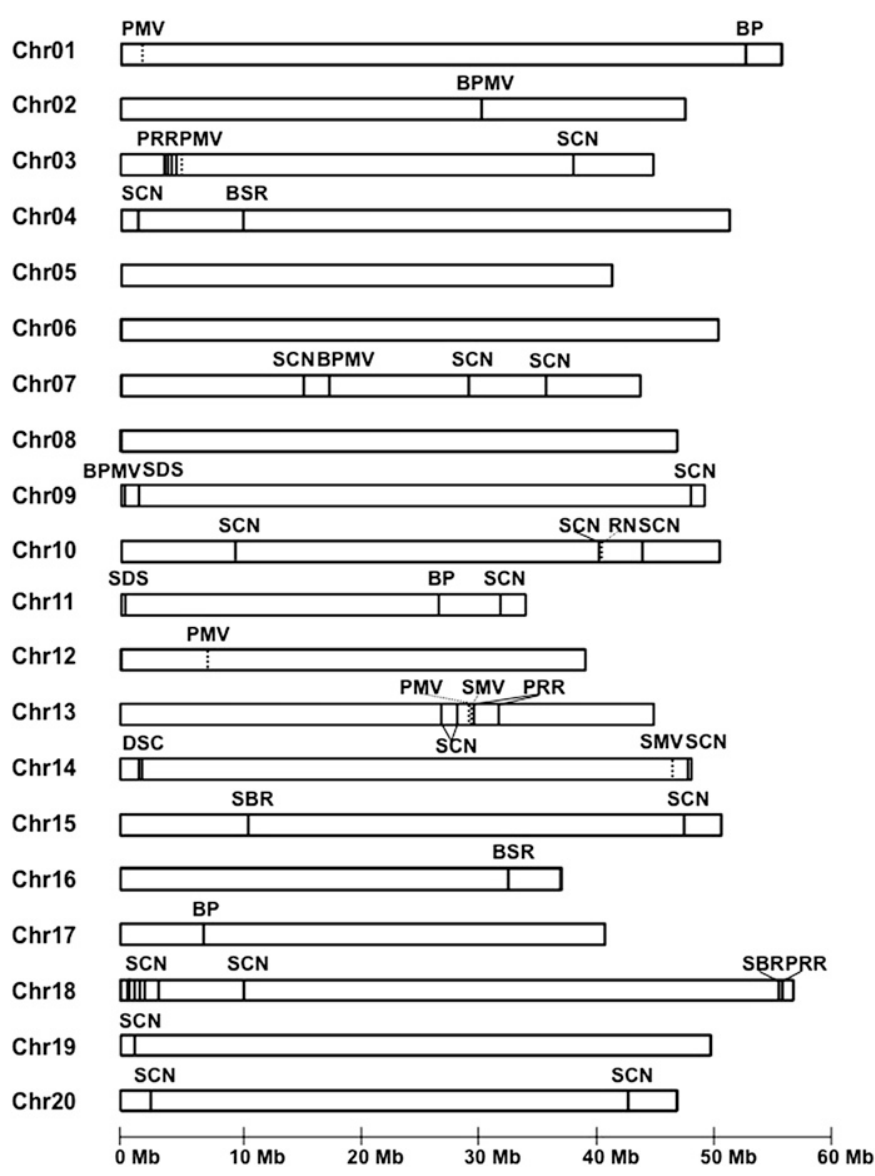

Fig. 1. Locations of significant single nucleotide polymorphisms (SNPs). Significant SNPs that at a 5\% false discovery rate are shown for 11 soybean diseases: bacterial pustule (BP), brown stem rot (BSR), Diaporthe stem canker (DSC), Phytophthora root and stem rot (PRR), sudden death syndrome (SDS), soybean rust (SBR), reniform nematode (RN), soybean cyst nematode (SCN), Bean pod mottle virus (BPMV), Peanut mottle virus (PMV), and Soybean mosaic virus (SMV). 
within the LD region of the most significant SNP (ss715580342) on chromosome 1 (Supplementary Fig. S2). Another SNP (ss715580344) within Glyma01g40560 was significant in the initial GWAS but not significant after including the peak SNP (ss715580342) as a covariate in the GWAS model. In addition, another LRR-RLK gene (Glyma11g20310) was found in the LD region of ss715609404 on chromosome 11 (Supplementary Fig. S3). A SNP (ss715628133) was found in the previously reported rxp locus, between SNUSNP17_2\&_12 and Satt372, where two candidate resistance genes (Glyma17g09780 and Glyma17g09790) were found (Kim et al. 2010). Interestingly, ss715628133 is located within the coding region of an RLK gene (Glyma17g09801) (Fig. 2 ). The result indicates Glyma17g09801 may contribute to resistance from the rxp locus along with Glyma17g09780 and Glyma17g09790.

BSR resistance. Two SNPs on chromosome 4 and 16 had significant associations with BSR. No defense-related genes were found in the LD region of ss715587043 on chromosome 4 (Supplementary Fig. S4), but more than 10 LRR-RLK genes were found in the LD region of ss715624573 on chromosome 16 (Supplementary Fig. S5), including Glyma16g28530, Glyma16g28540, and Glyma16g28570. These genes have been previously reported (Rincker et al. 2016a,b). It is likely that one or more of these LRR-RLK genes in this region may contribute to BSR resistance.

DSC resistance. Two SNPs, ss715617869 for D. phaseolorum var. caulivora and ss715617951 for D. phaseolorum var. meridionalis, were significant (Fig. 1). The LD regions of these two SNPs overlapped each other, suggesting the possibility that the same resistance source underlies these two SNPs. Although both SNPs were located within genes without LRR-domains, two LRRRLK genes (Glyma14g02850 and Glyma14g02990) and two Toll/interleukin-1 receptor (TIR)-NBS-LRR (Glyma.14g02760 and Glyma.14g02770) occurred between ss715617869 and ss715617951 (Fig. 3).

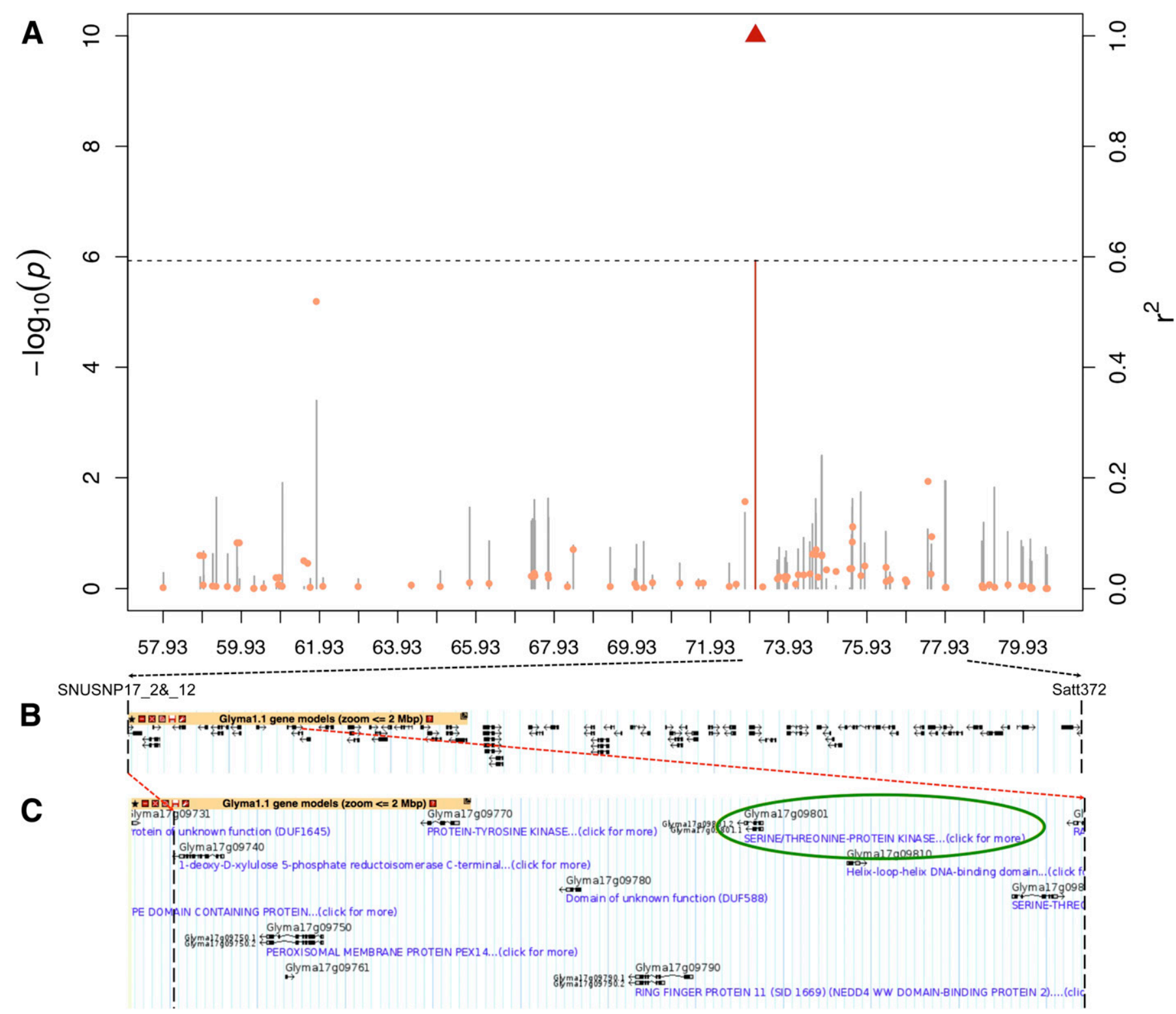

Fig. 2. Manhattan and linkage disequilibrium (LD) plots for single nucleotide polymorphism (SNP) ss715628133, associated with bacterial pustule resistance on soybean chromosome 17. A, Lines follow the left Y-axis, which shows $-\log 10$ ( $P$ values) for each SNP (each line). The red line indicates an SNP below a $5 \%$ false discovery rate (FDR)-adjusted $P$ value. The gray lines indicate SNPs with a FDR above 5\%-adjusted $P$ value. The horizontal dashed line indicates the minimum significant $P$ value at 5\% FDR. Dots follow the right Y-axis, which shows the LD $\left(\mathrm{r}^{2}\right)$ for each SNP corresponding to the most significant SNP (triangle). B, Genes located between SNUSNP17_2\&_12 to Satt372, which defined the region of the rxp locus. C, In addition to Glyma17g09780 and Glyma17g09790 reported by Kim et al. (2010), the receptor-like kinase gene Glyma17g09801 might be a candidate gene for the rxp locus. Images for B and C were captured from soybase.org. 


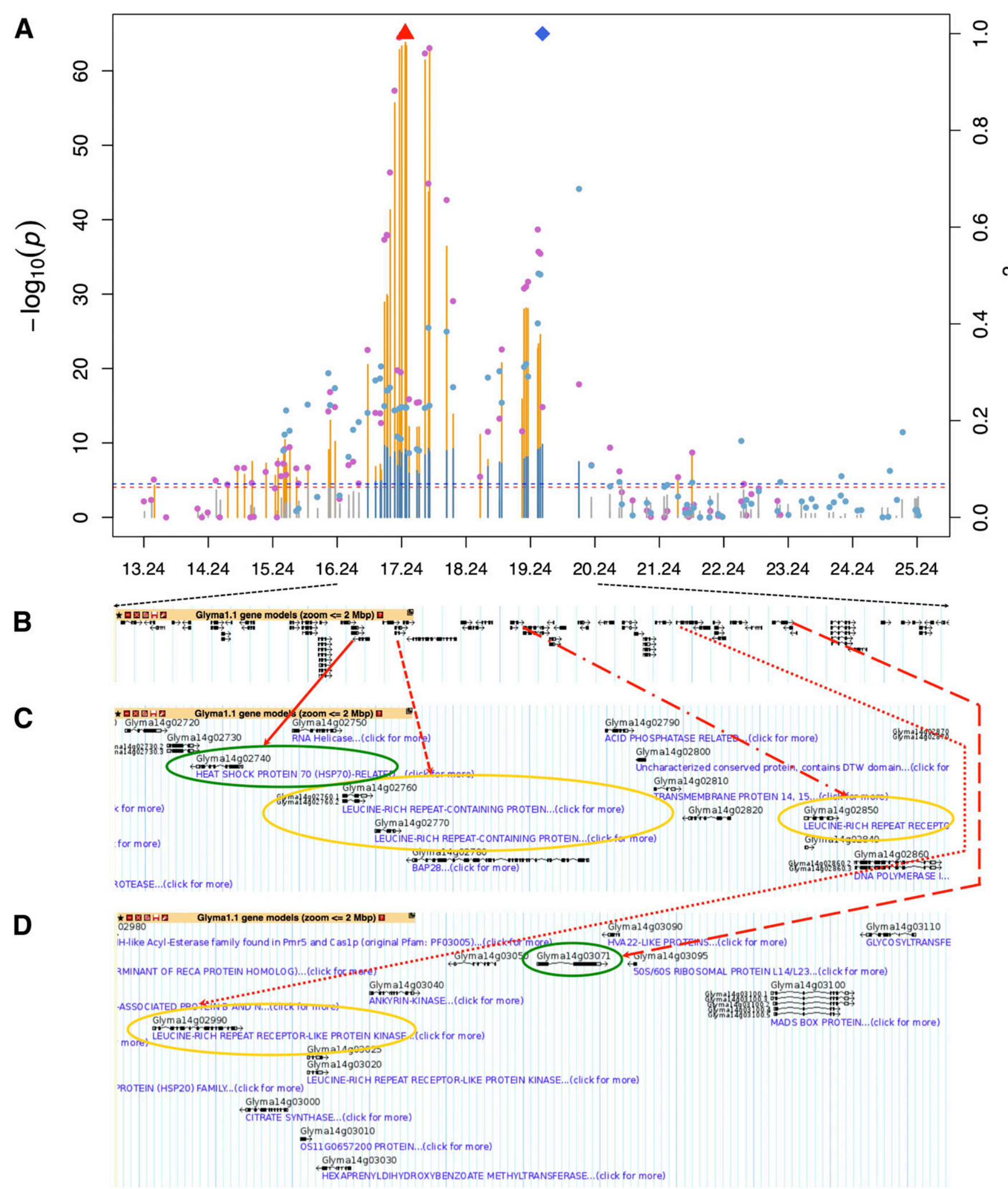

Fig. 3. Manhattan and linkage disequilibrium (LD) plots for single nucleotide polymorphism (SNP) ss715617869 (colors other than blue) and SNP ss715617951 (blue color), associated respectively with Northern and Southern Diaporthe stem canker resistance on soybean chromosome 14. A, Lines follow the left Y-axis, which shows the original $-\log 10$ ( $P$ values) for each SNP (each line). The colored lines indicate SNPs below a 5\% false discovery rate (FDR)-adjusted $P$ value. The gray lines indicate SNPs above 5\% FDR-adjusted $P$ value. The horizontal dashed line indicates the minimum significant $P$ value at 5\% FDR. Dots follow the right Y-axis, which shows the LD $\left(\mathrm{r}^{2}\right)$ for each SNP corresponding to the most significant SNP using D. phaseolorum var. caulivora (red triangle) and D. phaseolorum var. meridionalis (blue diamond). B, Genes located between 1,624,000 to 2,024,000 bp. C, ss715617869 locates within Glyma14g02740. Two toll interleukin 1 receptor-nucleotide binding site-leucine-rich repeat (LRR) and one LRR-receptor-like kinase (RLK) genes locate in the LD region of ss715617869. D, ss715617951 locates with Glyma14g03071, and a LRR-RLK locates before it in the LD region. Images for B through D were captured from soybase.org. 
PRR resistance. None of the tested SNPs were significantly associated with races $9,12,20,30,33$, and 38 . However, significant associations were detected for 19 SNPs on chromosome 3, using races 1 to $8,10,17,30$, and 30T. No SNPs were located between 4,041,000 and 4,441,000 bp (Supplementary Fig. S6A). A SNP (ss715585493) located within a LRR-RLK gene (Glyma03g03815) and five additional LRR-domain genes could be found in the LD region. A SNP (ss715586320) located within a LRR-RLK (Glyma03g04340) and four additional LRR-domain genes as well as other defense-related genes were observed in the $\mathrm{LD}$ region. Among the five significant SNPs on chromosome 13 associated with races 1, 25, and 31, SNP ss715614930 is located within a LRR-RLK gene (Glyma13g25750). Four additional LRRRLK genes (Glyma13g25724, Glyma13g25800, Glyma13g25811, and Glyma13g25820) and one NBS-LRR gene (Glyma13g25780) were found in the LD region surrounding the chromosome 13 peak SNP (ss715614930; Supplementary Fig. S7). Three of the four significant SNPs on chromosome 18 associated with races 1,4 , and 31 led to the identification of three NBS-LRR genes (Glyma18g51930, Glyma18g51950, and Glyma18g51960) and one LRR-RLK gene (Glyma18g52050) in the LD region of ss715632336 (Supplementary Fig. S8). Comparing these results to previous

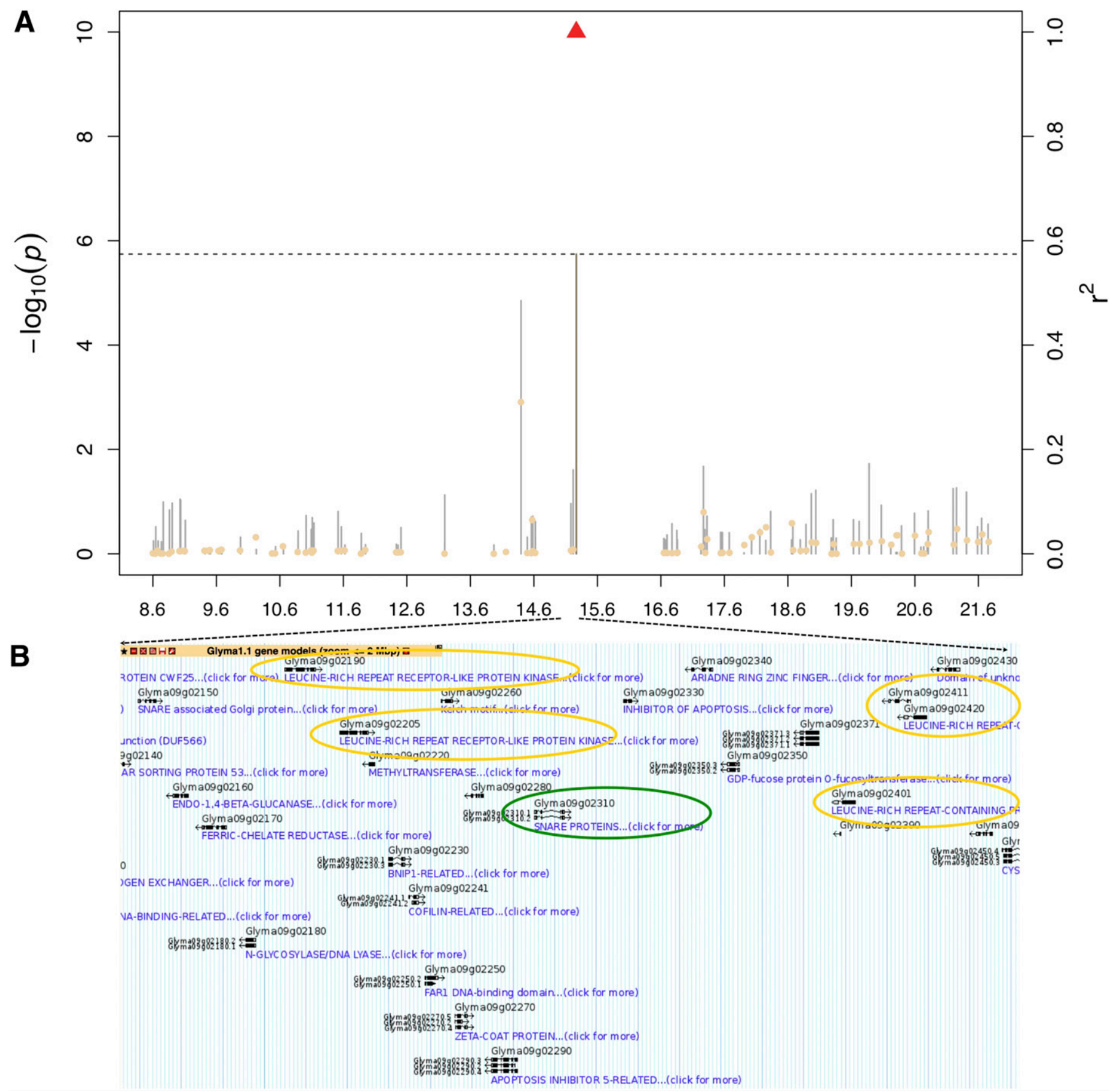

Fig. 4. Manhattan and linkage disequilibrium (LD) plots for single nucleotide polymorphism (SNP) ss715603096, associated with sudden death sydrome resistance on soybean chromosome 9. A, Lines follow the left Y-axis, which shows $-\log 10$ ( $P$ values) for each SNP (each line). The dark gray line indicates an SNP below a $5 \%$ false discovery rate (FDR)-adjusted $P$ value. The light gray lines indicate SNPs with FDR above 5\%-adjusted $P$ value. The horizontal dashed line indicates the minimum significant $P$ value at 5\% FDR. Dots follow the right Y-axis, which shows the LD $\left(\mathrm{r}^{2}\right)$ for each SNP corresponding to the most significant SNP (triangle). B, ss715603096 locates in Glyma09g02310 (green circle) and other leucine-rich repeat domain genes could be found in the LD region (yellow circles); image captured from soybase.org. 
reports, SNPs on chromosome 3 were likely mapped to be Rps 1 rather than $R p s 7$ because $R p s 7$ is not functional against races 1 to 8, 10, 17, 30, and 30T; instead, at least one allelic type of Rps 1 would be functional against these races (Lin et al. 2013; Sugimoto et al. 2012; Sun et al. 2011; Zhang et al. 2013). Comparison of the pathotypes did not provide insights for loci on chromosome 13 and 18.

SDS resistance. There were two significant SNPs, ss715603096 on chromosome 9 and ss 715609076 on chromosome 11, associated with resistance to SDS. While ss715603096 is located within a SNARE gene (Glyma09g02310), there was two LRR-RLK genes (Glyma.09g02190 and Glyma.09g02205) and three NBS-LRR genes (Glyma.09g02401, Glyma.09g02411, and Glyma.09g02420) located in the LD region of ss715603096 (Fig. 4). For chromosome 11, a NBS-LRR gene (Glyma11g17875) was found in the LD region of ss715609076 (Supplementary Fig. S9).

SBR resistance. None of the tested SNPs were significantly associated with leaf severity. Using RB, MIXED, and TAN phenotypes, one significant SNP (ss715620259) on chromosome 15 and one significant SNP (ss715632290) on chromosome 18 were identified. There were two LRR-RLK genes (Glyma15g14111 and
Glyma15g14121) in the LD region of ss715620259 (Supplementary Fig. S10). For ss715632290, located between two markers (BARC-010495-00656 and BARC-014379-01337) that border the Rppl locus (Chakraborty et al. 2009), there were two LRR-RLK genes (Glyma18g51330 and Glyma18g51520) and one NBS-LRR gene (Glyma18g51546) found in the LD region (Supplementary Fig. S11).

Root-knot nematode resistance. One SNP (ss715606985) on chromosome 10 was significantly associated with $\mathrm{RN}$ as well as SCN races 3 and 5. There was no LRR domain-encoding gene in the LD region of ss715606985 (Fig. 5), but other genes in the LD region, such as a tetratricpepyide repeat protein (Glyma10g31600) might be a plausible candidate if validated in future studies (Sharma and Pandey 2015).

SCN resistance. No significant SNPs were identified for races 2,4 , and 14 . There were several loci identified for race 1 (HG type 2, avirulent on Pickett), race 3 (HG type 0), and race 5 (HG type 2, virulent on Pickett) on chromosome $3,4,7,9$ to 11,13 to 15 , and 18 (Fig. 1). One of these SNPs (ss715629308) was found in the Rhgl locus on chromosome 18 for GWAS associated with races 1,3 , and 5 (Fig. 6). While the Rhgl locus (Cook et al. 2012) was found in a low

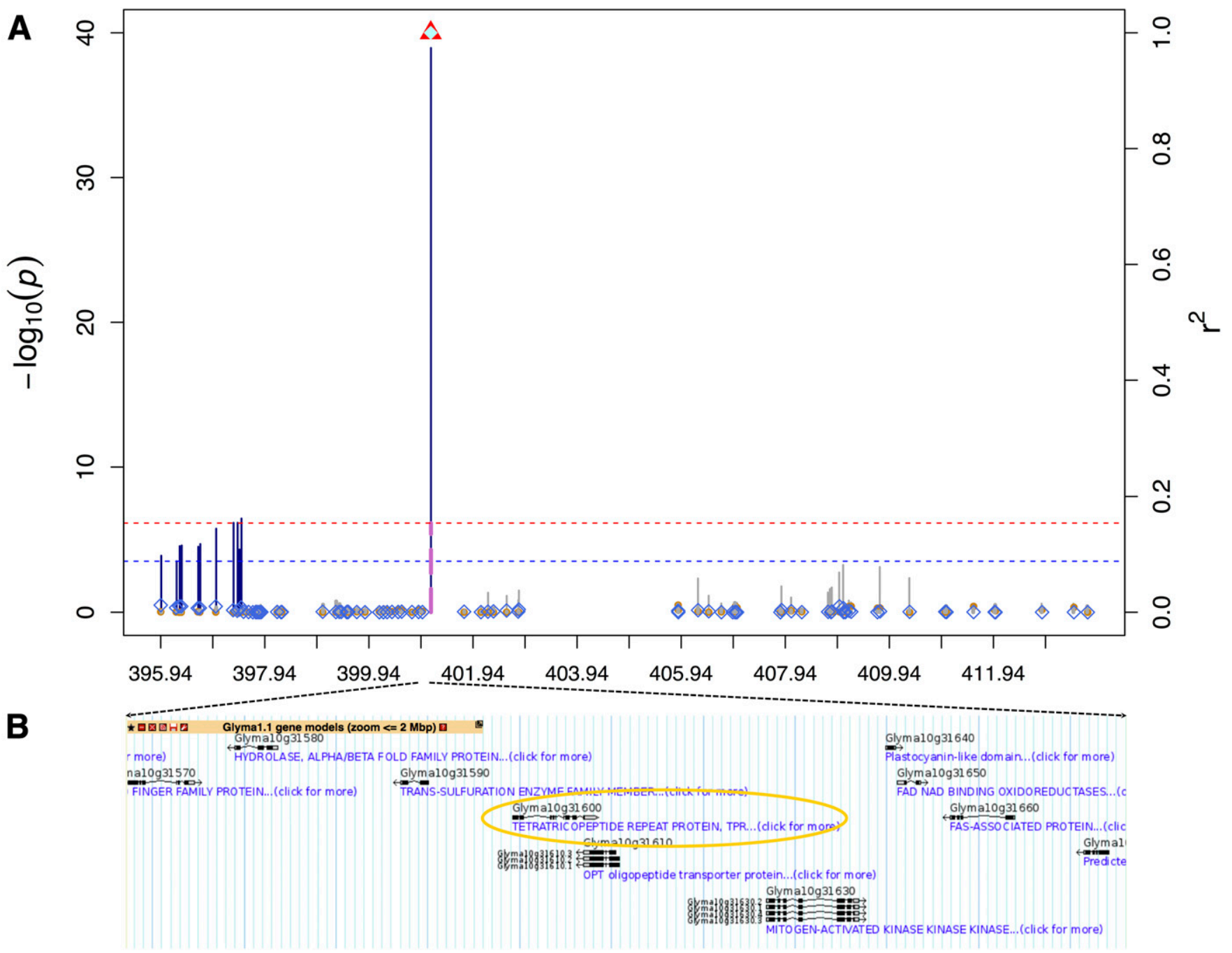

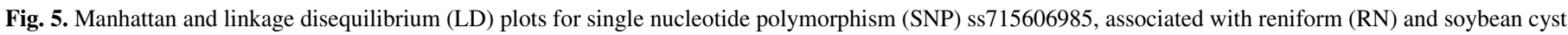

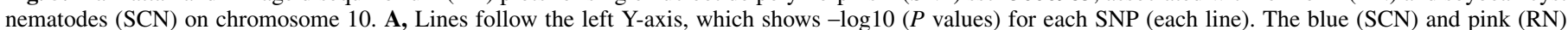

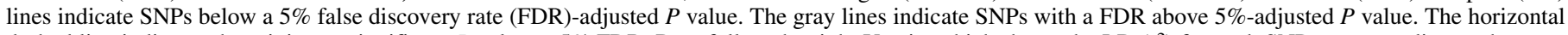

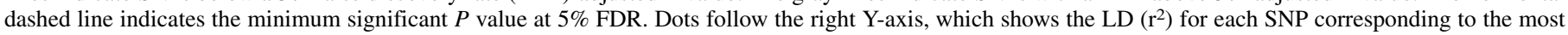

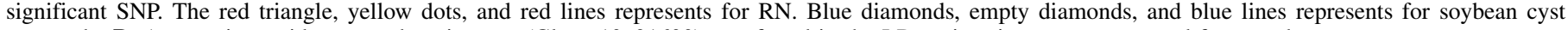
nematode. B, A tetratricpepyide repeat domain gene (Glyma10g31600) was found in the LD region; image was captured from soybase.org. 
LD region before ss715629308, there are five LRR-RLK genes in the high LD region after the SNP, with Glyma18g02681 being the closest to the SNP. Another significant SNP (ss715638409) on chromosome 20 was within the coding region of an LRR-RLK gene (Glyma20g33531), and three additional LRR-RLK were found in this LD region (Supplementary Fig. S12). These results indicate the possibility that resistance to SCN might embrace not only Rhgl copy number variation (Cook et al. 2012) but, also, LRR-RLKmediated defense resources (Afzal et al. 2009; Guo et al. 2006). There was no SNP found in the Rhg4 locus on chromosome 8 (Liu et al. 2012). Compared with the previous GWAS using race 3 (Han et al. 2015; Vuong et al. 2015), we found one significant SNP on chromosome 3 that was not previously reported. Our study appears to be the first mapping reported associated with races 1 and 5 (HG type 2), and we found significant SNPs on chromosome 4, 7, 10, 15, 18, and 19 (Fig. 1).

BPMV resistance. Three significant SNPs were found on chromosomes 2, 7, and 9 (Fig. 1). Four LRR-RLK genes (Glyma02g31410, Glyma107g17765, Glyma07g17910, and Glyma09g00540) were found in the LD region (Fig. 7; Supplementary

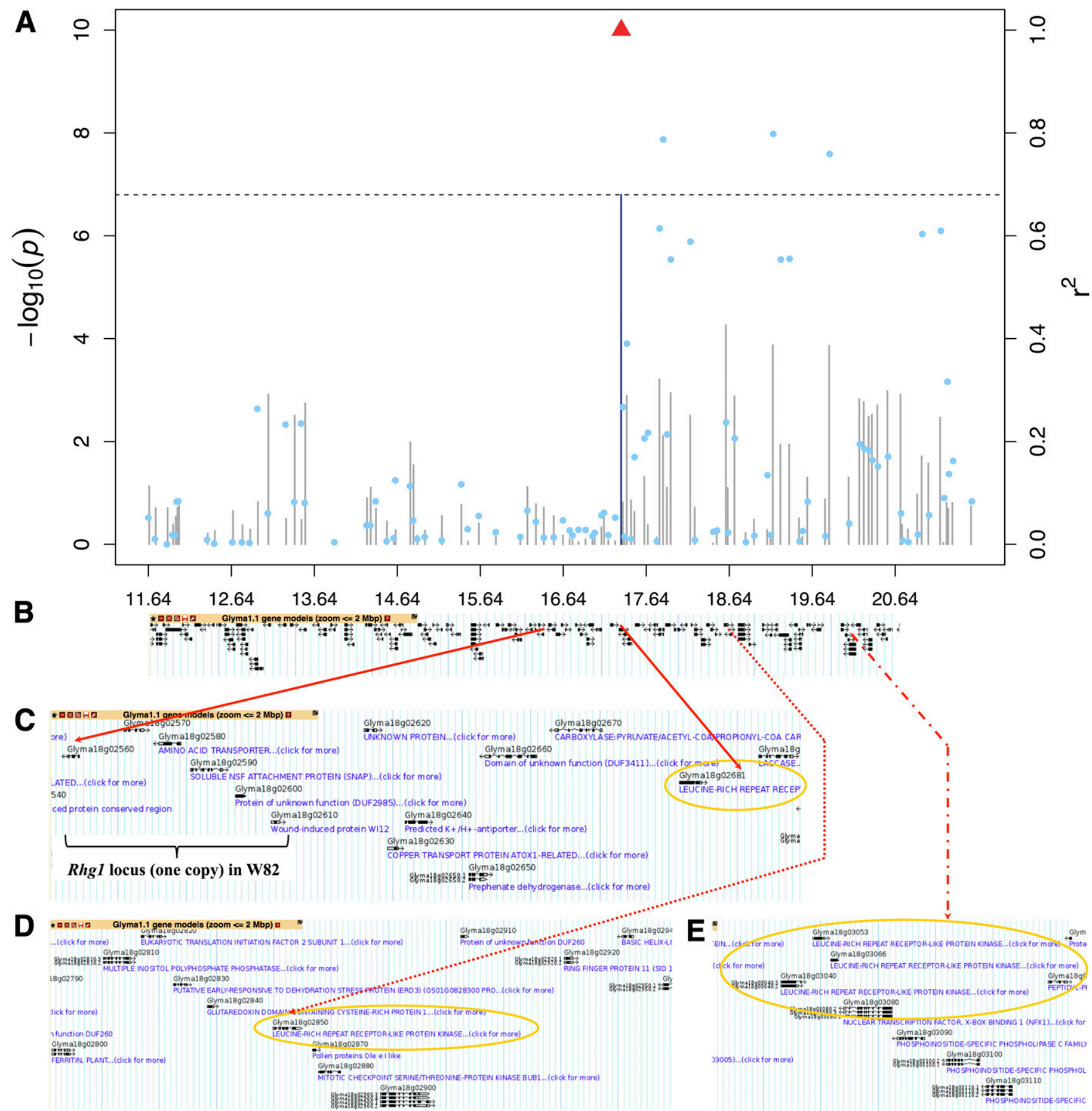

Fig. 6. Manhattan and linkage disequilibrium (LD) plots for single nucleotide polymorphism (SNP) ss715629308, associated with soybean cyst nematode resistance on soybean chromosome18. A, Lines follow the left Y-axis, which shows $-\log 10$ ( $P$ values) for each SNP (each line). The blue line indicates an SNP below a 5\% false discovery rate (FDR)-adjusted $P$ value; the gray lines indicate SNPs with a FDR above 5\%-adjusted $P$ value. The horizontal dashed line indicates the minimum significant $P$ value at 5\% FDR. Dots follow the right Y-axis, which shows the LD $\left(\mathrm{r}^{2}\right)$ for each SNP corresponding to the most significant SNP (triangle). B, Genes locate in 1,164,000 to 2,064,000 bp. C, A low LD region before ss715629308 includes the Rhgl locus. D to E, A high LD region after ss715629308 includes four additional leucine-rich repeat receptor-like kinase genes. Images for B through E were captured from soybase.org. 
Figs. S13 and S14), which suggests these genes might provide tolerance or resistance to BPMV.

PMV resistance. There were four significant SNPs for PMV (Supplementary Fig. S15). While no LRR-domain gene was found on chromosome 1, seven NBS-LRR genes (Glyma03g05260, Glyma03g05290, Glyma03g05351, Glyma03g05370, Glyma03g06385, Glyma03g05400, and Glyma03g05420) were found in the LD region to ss715586831 on chromosome 3 (Fig. 8). For the SNPs on chromosomes 12 and 13, one LRR-RLK gene (Glyma12g09960) and one LRR-RLK gene (Glyma13g24980), respectively, were found in the LD region (Supplementary Figs. S16 and S17). The significant SNP (ss715614803) on chromosome 13 was found within the coding region of a previously reported $R p v 1$ gene, and it is about $500 \mathrm{~kb}$ from another significantly associated SNP (ss715614889) located in the Rsvl locus for SMV (Supplementary
Fig. S18). This result supports a previous mapping study that suggested $R p v l$ is located in the vicinity of $R s v l$ (Gore et al. 2002).

SMV resistance. One significant SNP (ss715614889) on chromosome 13 was found using SMV strains G1, G2, and G3. There were one LRR-RLK gene (Glyma13g25340) and two NBS-LRR genes (Glyma13g25420 and Glyma13g25440) found in the LD region. It seems plausible that $R s v 1$ is underlying the signal at ss715614889, because almost all allelic types of $R s v 1$ are effective against SMV strains G1 to G3 (Cervantes-Martinez et al. 2015). In contrast, G7 has been shown to be the most virulent strain and only soybean lines with one or both $R s v 3$ or $R s v 4$ were reported resistant to G7 (Ilut et al. 2016). A SNP (ss715619353) on chromosome 14 was significantly associated with G7. Six NBS-LRR genes (Glyma14g38500, Glyma14g38516, Glyma14g38533, Glyma14g38561, Glyma14g38586, and Glyma14g38700) and three LRR-RLK genes

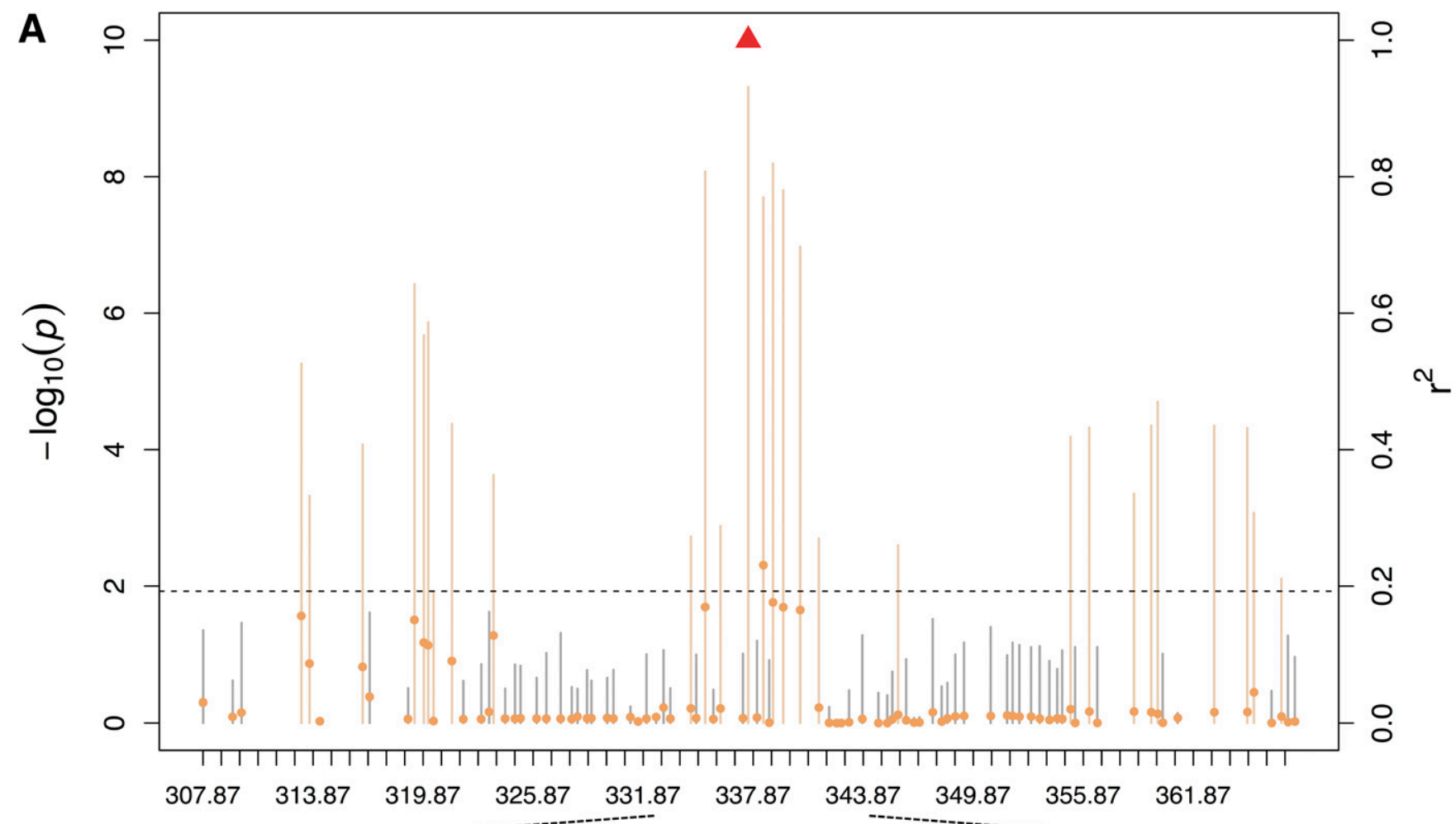

B

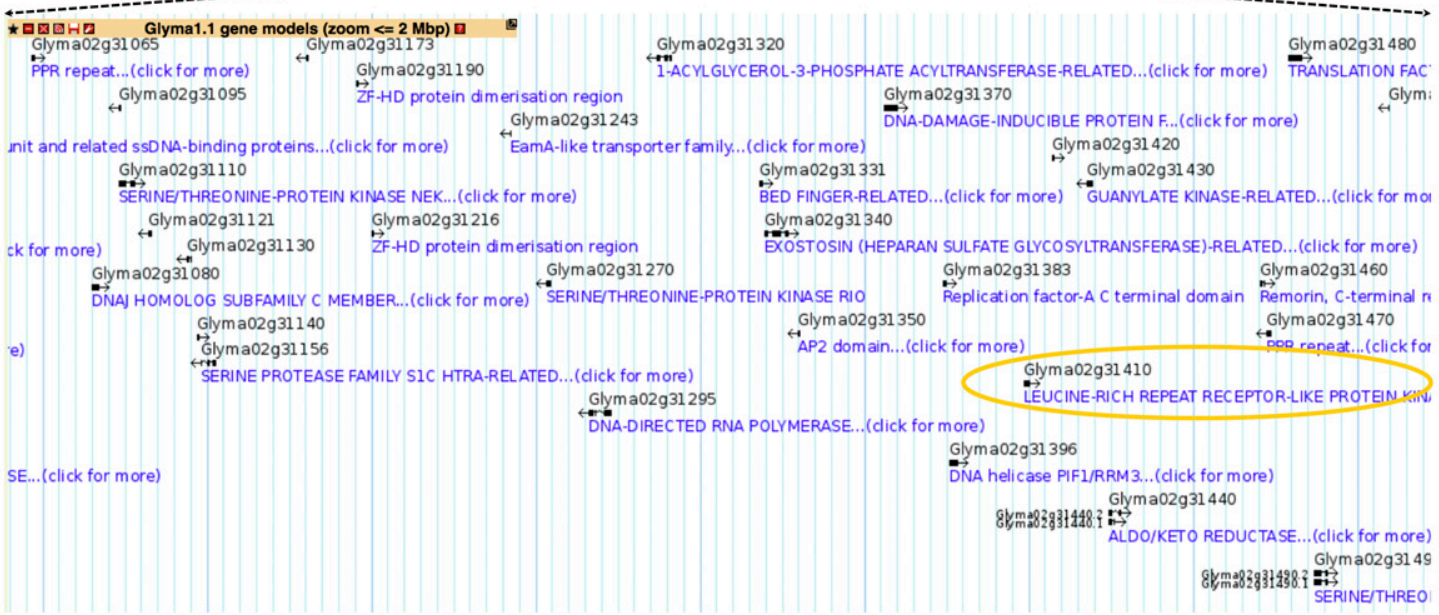

Fig. 7. Manhattan and linkage disequilibrium (LD) plots for single nucleotide polymorphism (SNP) ss715581912, associated with Bean pod mottle virus resistance on soybean chromosome 2. A, Lines follow the left Y-axis, which shows $-\log 10$ ( $P$ values) for each SNP (each line). The orange lines indicate SNPs below a 5\% false discovery rate (FDR)-adjusted $P$ value; dark gray lines indicate SNPs with a FDR above 5\%-adjusted $P$ value. The horizontal dashed line indicates the minimum significant $P$ value at 5\% FDR. Dots follow the right Y-axis, which shows the LD $\left(\mathrm{r}^{2}\right)$ for each SNP corresponding to the most significant SNP (triangle). B, A leucine-rich repeat receptor-like kinase (Glyma02g31410) was found in the LD region; image was captured from soybase.org. 
(Glyma14g38630, Glyma14g38650, and Glyma14g38670) were found in the LD region (Supplementary Fig. S19).

\section{DISCUSSION}

The availability of SoySNP50K provides insights into the resistance gene pool in the USDA Soybean Germplasm Collection and, also, enables genomic selection using these SNPs to predict genomic breeding values for diseases, as demonstrated for SDS and Tobacco ringspot virus (Bao et al. 2015; Chang et al. 2016a). With high throughput genotyping technologies, genotype-based selection is expected to streamline soybean resistance breeding. Nevertheless, some limitations of GWAS have been noted (Korte and Farlow 2013). In our study, we noticed that a larger population size was not a guarantee for finding significant results, although it generally increased statistical power and signal strength. For example, the USDA-ARS GRIN database contains a data set with 1,065 phenotyped soybean PIs for Pythium root rot but the GWAS failed to detect any significant SNPs. This was also true for frogeye leaf spot, using four data sets (1,332 PIs for Cercospora soja isolates C32; 1,902 PIs for $C$. soja race 2; 104 PIs for $C$. soja race 11 ; and 114 PIs (race unknown) in which they all failed to identify significant SNPs. In another example, an identical locus was found using either 1,426 or 112 PIs for DSC and the larger population (1,426 PIs) provided only better signal strength (Fig. 3). Moreover, a GWAS using only 79 PIs identified a SNP associated with RN, with this same SNP detected with SCN races 3 and 5, using 9,865 and 9,353 PIs, respectively (Fig. 5). In addition to our observations, recent studies used just 84 recombinant inbred lines to screen viral resistance in common bean using case-control GWAS (Hart and Griffiths 2015); and in an Arabidopsis study, immunity to Botrytis cinerea was based on a mapping population of 96 Arabidopsis accessions with a similar flowering time from the total collection of 241 accessions (Corwin et al. 2016). It therefore seems reasonable that a representative diversity panel may be equally important for a GWAS as a sufficient sample size.

A conventional cutoff at MAF 0.05 or 0.01 was used to filter SNPs. We observed several cases in which significant signals were

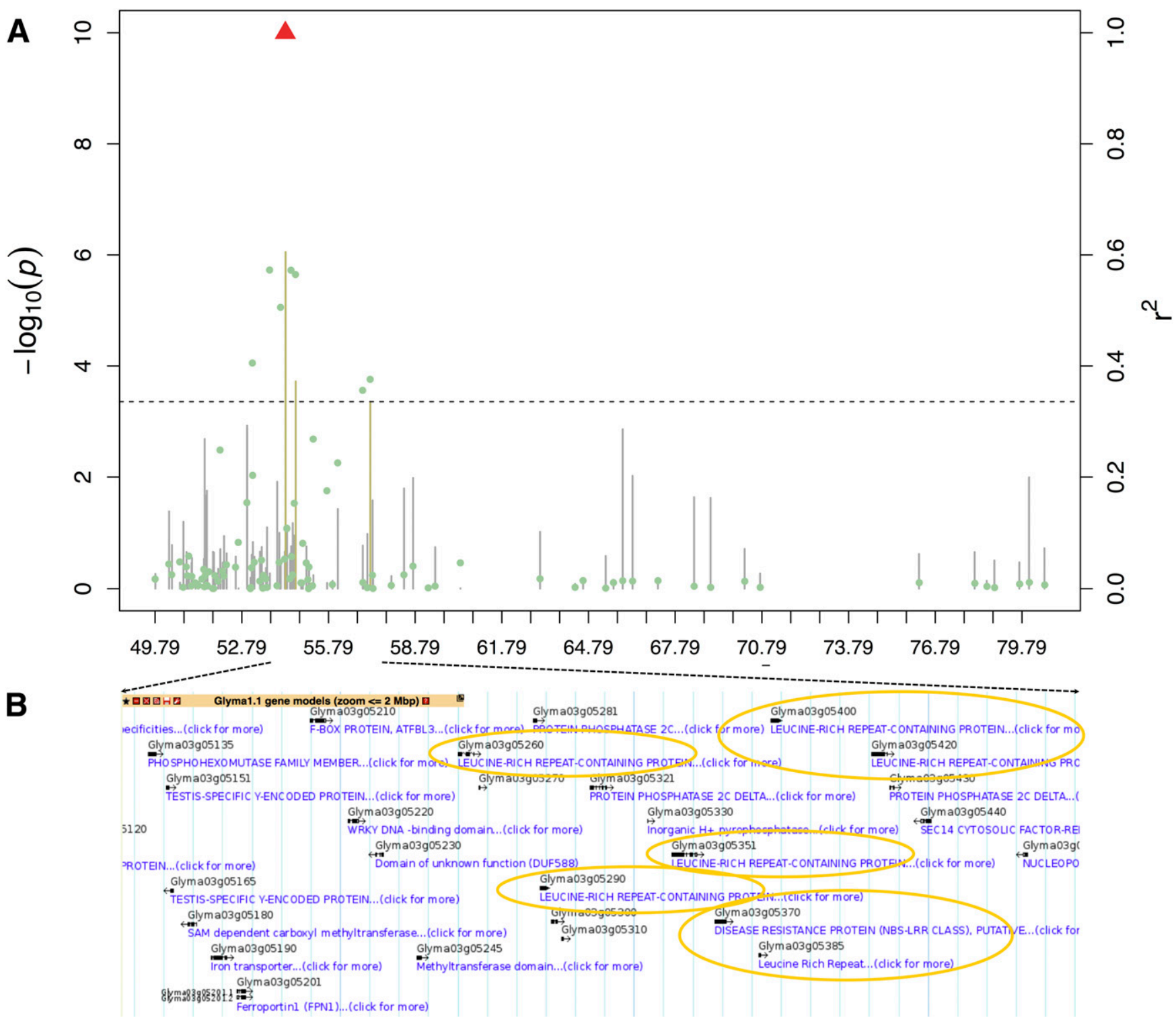

Fig. 8. Manhattan and linkage disequilibrium (LD) plots for single nucleotide polymorphism (SNP) ss715586831, associated with Peanut mottle virus resistance on soybean chromosome 3. A, Lines follow the left Y-axis, which shows - $\log 10$ ( $P$ values) for each SNP (each line). The green lines indicate SNPs below a 5\% false discovery rate (FDR)-adjusted $P$ value; gray lines indicate SNPs with a FDR above 5\%-adjusted $P$ value. The horizontal dashed line indicates the minimum significant $P$ value at 5\% FDR. Dots follow the right Y-axis, which shows the LD $\left(\mathrm{r}^{2}\right)$ for each SNP corresponding to the most significant SNP (triangle). B, Seven nucleotide-binding site leucine-rich repeat genes were found in the LD region; image was captured from soybase.org. 
detected but ignored because they were too rare in the population. For example, resistance to SDS in soybean is quantitative and sources of resistance to SDS in the USDA Soybean Germplasm Collection may be lower than 1\% (Mueller et al. 2002). The highly skewed phenotypic distribution toward susceptibility suggests that the associations of SNPs with SDS resistance are likely to be rare. Dozens of SNPs were significantly associated with SDS resistance in our study, but they were filtered out because most of them fell below the 0.01 MAF (Supplementary Fig. S20). Accordingly, the decision to choose a MAF cutoff has a profound impact on our GWAS, especially when resistance is rare. However, using all SNPs without setting a MAF threshold would introduce statistical problems. An alternative strategy is to balance the distribution by using a smaller proportion of susceptible PIs. For example, Zhang et al. (2015) selected 214 PIs, of which about $75 \%$ were susceptible to SDS according to the USDA-ARS GRIN database and, after reevaluating phenotypes of these PIs, they identified 12 loci and 12 SNP-SNP interactions associated with SDS resistance. While the strategy may provide a solution for increasing the proportion of resistant PIs and the frequency of rare resistant alleles in a population, it should be noted that results could differ based on selecting a different proportion of susceptible PIs.

In our study, we utilized phenotypic data from the USDA Soybean Germplasm Collection to conduct a GWAS for 11 diseases. We successfully identified SNPs located in previously reported resistance loci and reported novel associations. We demonstrated the power of the GWAS to identify several LRR-RLK and NBS-LRR genes within the LD regions of significant SNPs. Follow-up biological studies need to be conducted to understand how these candidate LRR-domain genes are involved in defense responses. Because of the decrease in costs associated with obtaining high-density genome-wide marker sets and the incremental improvements of statistical methods available for GWAS, challenges in the future may include the innovation of accurate, lowcost, high-throughput, and reproducible phenotyping, which together may launch a new wave of plant breeding and disease management for crops (Mahlein 2016; Singh et al. 2016).

\section{ACKNOWLEDGMENTS}

We thank the curators of the USDA-ARS GRIN (ars-grin.gov) and SoyBase and the Soybean Breeder's Toolbox (soybase.org) along with funding support from USDA ARS. Mention of a trademark, proprietary product, or vendor does not constitute a guarantee or warranty of the product by USDA-ARS or the University of Illinois and does not imply its approval to the exclusion of other products or vendors that may also be suitable.

\section{LITERATURE CITED}

Afzal, A. J., Natarajan, A., Saini, N., Iqbal, M. J., Geisler, M. E. I., Shemy, H. A., Mungur, R., Willmitzer, L., and Lightfoot, D. A. 2009. The nematode resistance allele at the rhgl locus alters the proteome and primary metabolism of soybean roots. Plant Physiol. 151:1264-1280.

Afzal, A. J., Wood, A. J., and Lightfoot, D. A. 2008. Plant receptor-like serine threonine kinases: Roles in signaling and plant defense. Mol. Plant-Microbe Interact. 21:507-517.

Anderson, C. A., Pettersson, F. H., Clarke, G. M., Cardon, L. R., Morris, A. P., and Zondervan, K. T. 2010. Data quality control in genetic case-control association studies. Nat. Protoc. 5:1564-1573.

Anderson, J., Akond, M., Kassem, M. A., Meksem, K., and Kantartzi, S. K. 2015. Quantitative trait loci underlying resistance to sudden death syndrome (SDS) in MD96-5722 by 'Spencer' recombinant inbred line population of soybean. 3 Biotech 5:203-210.

Bachman, M. S., Tamulonis, J. P., Nickell, C. D., and Bent, A. F. 2001. Molecular markers linked to brown stem rot resistance genes, $\operatorname{Rbs}(1)$ and $R b s(2)$, in soybean. Crop Sci. 41:527-535.

Bao, Y., Kurle, J. E., Anderson, G., and Young, N. D. 2015. Association mapping and genomic prediction for resistance to sudden death syndrome in early maturing soybean germplasm. Mol. Breed. 35:128.

Barabaschi, D., Tondelli, A., Desiderio, F., Volante, A., Vaccino, P., Vale, G., and Cattivelli, L. 2016. Next generation breeding. Plant Sci. 242:3-13.
Benavidez, R., Pioli, R. N., and Morandi, E. N. 2010. Response of the edamame edible soybean germplasm to Diaporthe phaseolorum, causal agent of soybean stem canker, in Argentina. Trop. Plant Pathol. 35: 48-51.

Benjamini, Y., and Hochberg, Y. 1995. Controlling the false discovery rate: A practical and powerful approach to multiple testing. J. R. Stat. Soc. B 1: 289-300.

Bernard, R. L., Smith, P. E., Kaufmann, M. J., and Schmitthenner, A. F. 1957. Inheritance of resistance to Phytophthora root rot and stem rot in the soybean. Agron. J. 49:391.

Bowers, G. R., Jr., Ngeleka, K., and Smith, O. D. 1993. Inheritance of stem canker resistance in soybean cultivars Crockett and Dowling. Crop Sci. 33: 67-70.

Bradbury, P. J., Zhang, Z., Kroon, D. E., Casstevens, T. M., Ramdoss, Y., and Buckler, E. S. 2007. TASSEL: Software for association mapping of complex traits in diverse samples. Bioinformatics 23:2633-2635.

Browning, B. L., and Browning, S. R. 2009. A unified approach to genotype imputation and haplotype-phase inference for large data sets of trios and unrelated individuals. Am. J. Hum. Genet. 84:210-223.

Cervantes-Martinez, I., Chen, P. Y., Orazaly, M., and Klepadlo, M. 2015. Identification of a new allele at the Rsv3 Locus for resistance to soybean mosaic virus in PI 61944 soybean accession. Crop Sci. 55:999-1005.

Chakraborty, N., Curley, J., Frederick, R. D., Hyten, D. L., Nelson, R. L., Hartman, G. L., and Diers, B. W. 2009. Mapping and confirmation of a new allele at Rppl from soybean PI 504538A conferring RB lesion type resistance to soybean rust. Crop Sci. 49:783-790.

Chang, H.-X., Brown, P., Lipka, A., Domier, L. L., and Hartman, G. L. 2016 a. Genome-wide association and genomic prediction identifies associated loci and predicts the sensitivity of Tobacco ringspot virus in soybean plant introductions. BMC Genomics 17:153.

Chang, H.-X., Domier, L. L., Radwan, O., Yendrek, C. R., Hudson, M. E., and Hartman, G. L. 2016b. Identification of multiple phytotoxins produced by Fusarium virguliforme including a phytotoxic effector FvNIS1 associated with sudden death syndrome foliar symptoms. Mol. Plant-Microbe Interact. 29:96-108.

Chawla, S., Bowen, C. R., Slaminko, T. L., Hobbs, H. A., and Hartman, G. L. 2013. A public program to evaluate commercial soybean cultivars for pathogen and pest resistance. Plant Dis. 97:568-578.

Chen, H. F., Zhao, S., Yang, Z. L., Sha, A. H., Wan, Q., Zhang, C. J., Chen, L. M., Yuan, S. L., Qiu, D. Z., Chen, S. L., Shan, Z. H., and Zhou, X. A. 2015. Genetic analysis and molecular mapping of resistance gene to Phakopsora pachyrhizi in soybean germplasm SX6907. Theor. Appl. Genet. 128:733-743.

Chiesa, M. A., Pioli, R. N., and Morandi, E. N. 2009. Specific resistance to soybean stem canker conferred by the Rdm4 locus. Plant Pathol. 58:10321038.

Cho, E. K., and Goodman, R. M. 1979. Strains of soybean mosaic virus classification based on virulence in resistant soybean cultivars. Phytopathology 69:467-470

Clarke, G. M., Anderson, C. A., Pettersson, F. H., Cardon, L. R., Morris, A. P., and Zondervan, K. T. 2011. Basic statistical analysis in genetic case-control studies. Nat. Protoc. 6:121-133.

Cleveland, W. S. 1981. LOWESS: A program for smoothing scatterplots by robust locally weighted regression. Am. Stat. 35:54.

Concibido, V. C., Diers, B. W., and Arelli, P. R. 2004. A decade of QTL mapping for cyst nematode resistance in soybean. Crop Sci. 44:1121-1131.

Cook, D. E., Lee, T. G., Guo, X. L., Melito, S., Wang, K., Bayless, A. M., Wang, J. P., Hughes, T. J., Willis, D. K., Clemente, T. E., Diers, B. W., Jiang, J. M., Hudson, M. E., and Bent, A. F. 2012. Copy number variation of multiple genes at Rhgl mediates nematode resistance in soybean. Science 338:1206-1209.

Corwin, J. A., Copeland, D., Feusier, J., Subedy, A., Eshbaugh, R., Palmer, C., Mallof, J., and Kliebenstein, D. J. 2016. The quantitative basis of the Arabidopsis innate immune system to endemic pathogens depends on pathogen genetics. PLoS Genet. 12:e1005789.

Firth, D. 1993. Bias reduction of maximum likelihood estimates. Biometrika 80:27-38.

Garcia, A., Calvo, E. S., Kiihl, R. A. D., Harada, A., Hiromoto, D. M., and Vieira, L. G. E. 2008. Molecular mapping of soybean rust (Phakopsora pachyrhizi) resistance genes: Discovery of a novel locus and alleles. Theor. Appl. Genet. 117:545-553.

Gore, M. A., Hayes, A. J., Jeong, S. C., Yue, Y. G., Buss, G. R., and Maroof, M. A. S. 2002. Mapping tightly linked genes controlling potyvirus infection at the Rsv1 and Rpv1 region in soybean. Genome 45:592-599.

Guo, B., Sleeper, D. A., Lu, P., Shannon, J. G., Nguyen, H. T., and Arelli, P. R. 2006. QTLs associated with resistance to soybean cyst nematode in soybeans: Meta-analysis of QTL locations. Crop Sci. 46:595-602.

Ha, B. K., Robbins, R. T., Han, F., Hussey, R. S., Soper, J. F., and Boerma, H. R. 2007. SSR mapping and confirmation of soybean QTL from PI 
437654 conditioning resistance to reniform nematode. Crop Sci. 47: 1336-1343.

Han, Y. P., Zhao, X., Cao, G. L., Wang, Y., Li, Y. H., Liu, D. Y., Teng, W. L., Zhang, Z. W., Li, D. M., Qiu, L. J., Zheng, H. K., and Li, W. B. 2015. Genetic characteristics of soybean resistance to HG type 0 and HG type 1.2.3.5.7 of the cyst nematode analyzed by genome-wide association mapping. BMC Genomics 16:598.

Hanson, P. M., Nickell, C. D., Gray, L. E., and Sebastian, S. A. 1988. Identification of 2 dominant genes conditioning brown stem rot resistance in soybean. Crop Sci. 28:41-43.

Harris, D. K., Kendrick, M. D., King, Z. R., Pedley, K. F., Walker, D. R., Cregan, P. B., Buck, J. W., Phillips, D. V., Li, Z., and Boerma, H. R. 2015. Identification of unique genetic sources of soybean rust resistance from the USDA Soybean Germplasm Collection. Crop Sci. 55:2161-2176.

Hart, J. P., and Griffiths, P. D. 2015. Genotyping-by-sequencing enabled mapping and marker development for the $B y$-2 Potyvirus resistance allele in common bean. Plant Genome 8. doi:10.3835/plantgenome2014.09.0058

Hartman, G. L., Chang, H. X., and Leandro, L. F. 2015. Research advances and management of soybean sudden death syndrome. Crop Prot. 73:60-66.

Hartman, G. L., Hill, C. B., Twizeyimana, M., Miles, M. R., and Bandyopadhyay, R. 2011. Interaction of soybean and Phakopsora pachyrhizi, the cause of soybean rust. Pages 1-13 in: CAB Reviews: Perspectives in Agriculture, Veterinary Science Nutrition and Natural Resources, Vol. 6. CAB International, Wallingford, U.K.

Hartwig, E. E., and Lehman, S. G. 1951. Inheritance of resistance to the bacterial pustule disease in soybeans. Agron. J. 43:226-229.

Hill, J. H., and Whitham, S. A. 2014. Control of virus diseases in soybeans. Adv. Virus Res. 90:355-390.

Hossain, M. M., Akamatsu, H., Morishita, M., Mori, T., Yamaoka, Y., Suenaga, K., Soares, R. M., Bogado, A. N., Ivancovich, A. J. G., and Yamanaka, N. 2014. Molecular mapping of Asian soybean rust resistance in soybean landraces PI 594767A, PI 587905 and PI 416764. Plant Pathol. 64: 147-156.

Hyten, D. L., Hartman, G. L., Nelson, R. L., Frederick, R. D., Concibido, V. C., Narvel, J. M., and Cregan, P. B. 2007. Map location of the Rpp1 locus that confers resistance to soybean rust in soybean. Crop Sci. 47:837-840.

Hyten, D. L., Smith, J. R., Frederick, R. D., Tucker, M. L., Song, Q. J., and Cregan, P. B. 2009. Bulked segregant analysis using the GoldenGate assay to locate the Rpp3 locus that confers resistance to soybean rust in soybean. Crop Sci. 49:265-271.

Ilut, D. C., Lipka, A. E., Jeong, N., Bae, D. N., Kim, D. H., Kim, J. H., Redekar, N., Yang, K., Park, W., Kang, S.-T., Kim, N., Moon, J.-K., Saghai Maroof, M. A., Gore, M. A., and Jeong, S.-C. 2016. Identification of haplotypes at the Rsv4 genomic region in soybean associated with durable resistance to soybean mosaic virus. Theor. Appl. Genet. 129:453-468.

Jiao, Y. Q., Vuong, T. D., Liu, Y., Li, Z. L., Noe, J., Robbins, R. T., Joshi, T., $\mathrm{Xu}$, D., Shannon, J. G., and Nguyen, H. T. 2015a. Identification of quantitative trait loci underlying resistance to southern root-knot and reniform nematodes in soybean accession PI 567516C. Mol. Breed. 35:131.

Jiao, Y. Q., Vuong, T. D., Liu, Y., Meinhardt, C., Joshi, T., Cregan, P. B., Xu, D., Shannon, J. G., and Nguyen, H. T. 2015b. Identification and evaluation of quantitative trait loci underlying resistance to multiple HG types of soybean cyst nematode in soybean PI 437655. Theor. Appl. Genet. 128: 15-23.

Kang, Y. J., Kim, K. H., Shim, S., Yoon, M. Y., Sun, S., Kim, M. Y., Van, K., and Lee, S. H. 2012. Genome-wide mapping of NBS-LRR genes and their association with disease resistance in soybean. BMC Plant Biol. 12:139.

Kelly, H. Y., Dufault, N. S., Walker, D. R., Isard, S. A., Schneider, R. W., Giesler, L. J., Wright, D. L., Marios, J. J., and Hartman, G. L. 2015. From select agent to an established pathogen, the response to Phakopsora pachyrhizi in North America. Phytopathology 105:905-916.

Kiihl, R. A. S., and Hartwig, E. E. 1979. Inheritance of reaction to soybean mosaic virus in soybeans. Crop Sci. 19:372.

Kilen, T. C., and Hartwig, E. E. 1987. Identification of single genescontrolling resistance to stem canker in soybean. Crop Sci. 27:863-864.

Kim, D. H., Kim, K. H., Van, K., Kim, M. Y., and Lee, S. H. 2010. Fine mapping of a resistance gene to bacterial leaf pustule in soybean. Theor. Appl. Genet. 120:1443-1450.

Kim, K., Park, J., Kim, M., Heu, S., and Lee, S. 2011. Genetic mapping of novel symptom in response to soybean bacterial leaf pustule in PI 96188. J. Crop Sci. Biotechnol. 14:119-123.

King, Z. R., Harris, D. K., Pedley, K. F., Song, Q., Wang, D., Wen, Z., Buck, J. W., Li, Z., and Boerma, H. R. 2016. A novel Phakopsora pachyrhizi resistance allele (Rpp) contributed by PI 567068A. Theor. Appl. Genet. 129: 517-534.

Korte, A., and Farlow, A. 2013. The advantages and limitations of trait analysis with GWAS: A review. Plant Methods 9:29.

Lee, S., Mian, M. A. R., McHale, L. K., Wang, H. H., Wijeratne, A. J., Sneller, C. H., and Dorrance, A. E. 2013. Novel quantitative trait loci for partial resistance to Phytophthora sojae in soybean PI 398841. Theor. Appl. Genet. 126:1121-1132.

Lehman, S. G., and Woodside, J. W. 1929. Varietal resistance of soybean to the bacterial pustule disease. J. Agr. Res. 39:795-804.

Li, K., Ren, R., Adhimoolam, K., Gao, L., Yuan, Y., Liu, Z., Zhong, Y., and Zhi, H. 2015. Genetic analysis and identification of two soybean mosaic virus resistance genes in soybean Glycine max (L.) Merr. Plant Breed. 134: 684-695.

Lightfoot, D. A. 2015. Two decades of molecular marker-assisted breeding for resistance to soybean sudden death syndrome. Crop Sci. 55:1460-1484.

Lin, F., Zhao, M. X., Ping, J. Q., Johnson, A., Zhang, B., Abney, T. S., Hughes, T. J., and Ma, J. X. 2013. Molecular mapping of two genes conferring resistance to Phytophthora sojae in a soybean landrace PI 567139B. Theor. Appl. Genet. 126:2177-2185.

Lipka, A. E., Kandianis, C. B., Hudson, M. E., Yu, J., Drnevich, J., Bradvury, P. J., and Gore, M. A. 2015. From association to prediction: Statistical methods for the dissection and selection of complex traits in plants. Curr. Opin. Plant Biol. 24:110-118.

Lipka, A. E., Tian, F., Wang, Q. S., Peiffer, J., Li, M., Bradbury, P. J., Gore, M. A., Buckler, E. S., and Zhang, Z. W. 2012. GAPIT: Genome association and prediction integrated tool. Bioinformatics 28:2397-2399.

Liu, J., Chen, N., Grant, J. N., Cheng, Z. M., Stewart, C. N., Jr., and Hewezi, T. 2015. Soybean kinome: Functional classification and gene expression patterns. J. Exp. Bot. 66:1919-1934.

Liu, S. M., Kandoth, P. K., Warren, S. D., Yeckel, G., Heinz, R., Alden, J., Yang, C. L., Jamai, A., El-Mellouki, T., Juvale, P. S., Hill, J., Baum, T. J., Cianzio, S., Whitham, S. A., Korkin, D., Mitchum, M. G., and Meksem, K. 2012. A soybean cyst nematode resistance gene points to a new mechanism of plant resistance to pathogens. Nature 492:256-260.

Luckew, A. S., Leandro, L. F., Bhattacharyya, M. K., Nordman, D. J., Lightfoot, D. A., and Cianzio, S. R. 2013. Usefulness of 10 genomic regions in soybean associated with sudden death syndrome resistance. Theor. Appl. Genet. 126:2391-2403.

Mahlein, A.-K. 2016. Plant disease detection by imaging sensors-Parallels and specific demands for precision agriculture and plant phenotyping. Plant Dis. 100:241-251

McLean, R. J., and Byth, D. E. 1980. Inheritance of resistance to rust (Phakopsora pachyrhizi) in soybeans. Aust. J. Agric. Res. 31:951-956.

Monteros, M. J., Missaoi, A. M., Phillips, D. V., Walker, D. R., and Boerma, H. R. 2007. Mapping and confirmation of 'Hyuuga' red-brown lesion resistance gene for Asian soybean rust. Crop Sci. 47:829-836

Mueller, D. S., Hartman, G. L., Nelson, R. L., and Pedersen, W. L. 2002. Evaluation of Glycine max germ plasm for resistance to Fusarium solani f. sp. glycines. Plant Dis. 86:741-746.

Narvel, J. M., Jakkula, L. R., Phillips, D. V., Wang, T., Lee, S. H., and Boerma, H. R. 2001. Molecular mapping of Rxp conditioning reaction to bacterial pustule in soybean. J. Hered. 92:267-270.

Nguyen, V. T., Vuong, T. D., VanToai, T., Lee, J. D., Wu, X., Mian, M. A. R., Dorrance, A. E., Shannon, J. G., and Nguyen, H. T. 2012. Mapping of quantitative trait loci associated with resistance to Phytophthora sojae and flooding tolerance in soybean. Crop Sci. 52:2481-2493.

Pioli, R. N., Morandi, E. N., Martinez, M. C., Lucca, F., Tozzini, A., Bisaro, V., and Hopp, H. E. 2003. Morphologic, molecular, and pathogenic characterization of Diaporthe phaseolorum variability in the core soybeanproducing area of Argentina. Phytopathology 93:136-146.

Price, A. L., Patterson, N. J., Plenge, R. M., Weinblatt, M. E., Shadick, N. A., and Reich, D. 2006. Principal components analysis corrects for stratification in genome-wide association studies. Nat. Genet. 38:904-909.

Rincker, K., Diers, B. W., and Hartman, G. L. 2016a. Fine mapping of resistance genes from five brown stem rot resistance sources in soybean. Plant Genome 9. doi:10.3835/plantgenome2015.08.0063

Rincker, K., Lipka, A. E., and Diers, B. W. 2016b. Genome-wide association study of brown stem rot resistance in soybean across multiple populations. Plant Genome 9. doi:10.3835/plantgenome2015.08.0064

Schmutz, J., Cannon, S. B., Schlueter, J., Ma, J., Mitros, T., Nelson, W., Hyten, D. L., Song, Q., Thelen, J. J., Cheng, J., Xu, D., Hellsten, U., May, G. D., Yu, Y., Sakurai, T., Umezawa, T., Bhattacharyya, M. K., Sandu, D., Valliyodan, B., Lindquist, E., Peto, M., Grant, D., Shu, S., Goodstein, D., Barry, K., Futrell-Griggs, M., Abernathy, B., Du, J., Tian, Z., Zhu, L., Gill, N., Joshi, T., Libault, M., Sethuraman, A., Zhang, X., Shinozaki, K., Nguyen, H. T., Wing, R. A., Cregan, P., Specht, J., Grimwood, J., Rokhsar, D., Stacey, G., Shoemaker, R. C., and Jackson, S. A. 2010. Genome sequence of the palaeopolyploid soybean. Nature 463:178-183.

Segura, V., Vilhjálmsson, B. J., Platt, A., Korte, A., Seren, U., Long, Q., and Nordborg, M. 2012. An efficient multi-locus mixed-model approach for genome-wide association studies in structured populations. Nat. Genet. 44: $825-830$

Sharma, M., and Pandey, G. K. 2015. Expansion and function of repeat domain proteins during stress and development in plants. Front. Plant Sci. 6:1218. 
Silva, D. C. G., Yamanaka, N., Brogin, R. L., Arias, C. A. A., Nepomuceno, A. L., Di Mauro, A. O., Pereira, S. S., Nogueira, L. M., Passianotto, A. L. L., and Abdelnoor, R. V. 2008. Molecular mapping of two loci that confer resistance to Asian rust in soybean. Theor. Appl. Genet. 117:57-63.

Singh, A., Ganapathysubramanian, B., Singh, A. K., and Sarkar, S. 2016. Machine learning for high-throughput stress phenotyping in plants. Trends Plant Sci. 21:110-124.

Smýkal, P., Coyne, C. J., Ambrose, M. J., Maxted, N., Schaefer, H., Blair, M. W., Berger, J., Greene, S. L., Nelson, M. N., Besharat, N., Vymyslicky, T., Toker, C., Saxena, R. K., Roorkiwal, M., Pandey, M. K., Hu, J. G., Li, Y. H., Wang, L. X., Guo, Y., Qiu, L. J., Redden, R. J., and Varshney, R. K. 2015. Legume crops phylogeny and genetic diversity for science and breeding. Crit. Rev. Plant Sci. 34:43-104.

Song, Q. J., Hyten, D. L., Jia, G. F., Quigley, C. V., Fickus, E. W., Nelson, R. L., and Cregan, P. B. 2013. Development and evaluation of soysnp50k, a high-density genotyping array for soybean. PLoS One 8:12.

Sugimoto, T., Kato, M., Yoshida, S., Matsumoto, I., Kobayashi, T., Kaga, A., Hajika, M., Yamamoto, R., Watanabe, K., Aino, M., Matoh, T., Walker, D. R., Biggs, A. R., and Ishimoto, M. 2012. Pathogenic diversity of Phytophthora sojae and breeding strategies to develop Phytophthora-resistant soybeans. Breed. Sci. 61:511-522.

Sun, J. T., Li, L. H., Zhao, J. M., Huang, J., Yan, Q., Xing, H., and Guo, N. 2014. Genetic analysis and fine mapping of RpsJS, a novel resistance gene to Phytophthora sojae in soybean Glycine max (L.). Merr. Theor. Appl. Genet. 127:913-919.

Sun, S., Wu, X. L., Zhao, J. M., Wang, Y. C., Tang, Q. H., Yu, D. Y., Gai, J. Y., and Xing, H. 2011. Characterization and mapping of RpsYu25, a novel resistance gene to Phytophthora sojae. Plant Breed. 130:139-143.

Swaminathan, S., Abeysekara, N. S., Liu, M., Cianzio, S. R., and Bhattacharyya, M. K. 2016. Quantitative trait loci underlying host responses of soybean to Fusarium virguliforme toxins that cause foliar sudden death syndrome. Theor. Appl. Genet. 129:495-506.

Tyler, J. M. 1996. Characterization of stem canker resistance in 'Hutcheson' soybean. Crop Sci. 36:591-593.

Van, K., Ha, B. K., Kim, M. Y., Moon, J. K., Paek, N. C., Heu, S., and Lee, S. H. 2004. SSR mapping of genes conditioning soybean resistance to six isolates of Xanthomonas axonopodis pv. glycines. Korean J. Genet. 26:47-54.

VanRaden, P. M. 2008. Efficient methods to compute genomic predictions. J. Dairy Sci. 91:4414-4423.

Vuong, T. D., Sonah, H., Meinhardt, C. G., Deshmukh, R., Kadam, S., Nelson, R. L., Shannon, J. G., and Nguyen, H. T. 2015. Genetic architecture of cyst nematode resistance revealed by genome-wide association study in soybean. BMC Genomics 16:593.

Wang, J. X., Joshi, T., Valliyodan, B., Shi, H. Y., Liang, Y. C., Nguyen, H. T., Zhang, J., and Xu, D. 2015. A Bayesian model for detection of high-order interactions among genetic variants in genome-wide association studies. BMC Genomics 16:20.
Webb, D. M. 1997. Brown stem rot resistance in soybeans. United States Patent 2281.

Wen, Z. X., Tan, R. J., Yuan, J. Z., Bales, C., Du, W. Y., Zhang, S. C., Chilvers, M. I., Schmidt, C., Song, Q. J., Cregan, P. B., and Wang, D. C. 2014. Genome-wide association mapping of quantitative resistance to sudden death syndrome in soybean. BMC Genomics 15:809.

Willmont, D. B., and Nickell, C. D. 1989. Genetic-analysis of brown stem rot resistance in soybean. Crop Sci. 29:672-674.

Woodworth, C. M., and Brown, F. C. 1920. Studies on varietal resistance and susceptibility to bacterial blight of soybeans. Phytopathology Abstr. 10: 68

Wu, X. L., Blake, S., Sleper, D. A., Shannon, J. G., Cregan, P., and Nguyen, H. T. 2009. QTL, additive and epistatic effects for SCN resistance in PI 437654. Theor. Appl. Genet. 118:1093-1105.

Yang, H. A., Li, C. D., Lam, H. M., Clements, J., Yan, G. J., and Zhao, S. C. 2015. Sequencing consolidates molecular markers with plant breeding practice. Theor. Appl. Genet. 128:779-795.

Yin, T. F., Cook, D., and Lawrence, M. 2012. ggbio: An R package for extending the grammar of graphics for genomic data. Genome Biol. 13: R77.

Yu, J., Pressoir, G., Briggs, W. H., Vroh Bi, I., Yamasaki, M., Doebley, J. F., McMullen, M. D., Gaut, B. S., Nielsen, D. M., Holland, J. B., Kresovich, S., and Buckler, E. S. 2006. A unified mixed-model method for association mapping that accounts for multiple levels of relatedness. Nat. Genet. 38: 203-208.

Zhang, J., Singh, A., Mueller, D. S., and Singh, A. K. 2015. Genome-wide association and epistasis studies unravel the genetic architecture of sudden death syndrome resistance in soybean. Plant J. Published online. doi: 10.1111/tpj.13069

Zhang, J. Q., Xia, C. J., Wang, X. M., Duan, C. X., Sun, S. L., Wu, X. F., and Zhu, Z. D. 2013. Genetic characterization and fine mapping of the novel Phytophthora resistance gene in a Chinese soybean cultivar. Theor. Appl. Genet. 126:1555-1561.

Zhang, Z., Ersoz, E., Lai, C. Q., Todhunter, R. J., Tiwari, H. K., Gore, M. A., Bradbury, P. J., Yu, J., Arnett, D. K., Ordovas, J. M., and Buckler, E. S. 2010. Mixed linear model approach adapted for genome-wide association studies. Nat. Genet. 42:355-360.

Zhou, G. C., Shao, Z. Q., Ma, F. F., Wu, P., Wu, X. Y., Xie, Z. Y., Yu, D. Y., Cheng, H., Liu, Z. H., Jiang, Z. F., Chen, Q. S., Wang, B., and Chen, J. Q. 2015. The evolution of soybean mosaic virus: An updated analysis by obtaining 18 new genomic sequences of Chinese strains/isolates. Virus Res. 208:189-198.

Zhou, X., and Stephens, M. 2014. Efficient multivariate linear model algorithms for genome-wide association studies. Nat. Methods 11:407411.

Zondervan, K. T., and Cardon, L. R. 2007. Designing candidate gene and genome-wide case-control association studies. Nat. Protoc. 2:2492-2501. 